In summary, following a single oral dose of DCA to laboratory rats, peak hepatic tissue DCA concentration occurred at $3 \mathrm{hr}$. When given chronically for 7 days, DCA caused activation of the pyruvate dehydrogenase complex which returned to basal activity $24 \mathrm{hr}$ following the final dose. Hepatic tissue DCA concentrations were maximally increased at $3 \mathrm{hr}$ following the final dose, and the drug was eliminated slowly over $72 \mathrm{hr}$ with a half-life of $9.74 \mathrm{hr}$. Liver and muscle showed similar DCA tissue concentrations following chronic administration.

Acknowledgements - The author thanks Dr. Grant Wilkinson and Brendan McAllister for their assistance in determining DCA concentrations, Glenna Jarrett for technical assistance, and Barbara Page for preparing the manuscript. This project was supported in part by a grant from the Muscular Dystrophy Association.

\section{Department of Neurology \\ Jerry Lewis Neuromuscular \\ Research Center \\ Vanderbilt University Medical \\ Center \\ Nashville, TN 37212, U.S.A.}

OWEn B. Evans*

* Correspondence should be sent to: Owen B. Evans, M.D., Department of Neurology, Vanderbilt University, Medical Center South, 2100 Pierce Ave., Nashville, TN 37212, U.S.A.

\section{REFERENCES}

1. S. Whitehouse and R. J. Randle, Biochem. J. 134, 651 (1973).

2. S. Whitehouse, R. H. Cooper and P. J. Randle, Biochem. J. 141, 761 (1974).

3. P. G. Wells, G. W. Moore, G. R. Wilkinson, D. Rabin, J. A. Oates and P. W. Stacpoole, Diabetologia 19, 109 (1980).

4. P. W. Stacpoole, G. W. Moore and D. M. Kornhauser, New Engl. J. Med. 298, 526 (1978).

5. A. McAllister, S. Allison and P. Randle, Biochem. J. 134, 1067 (1973).

6. G. Ribes, G. Valette and M. Loubatieres-Mariani, Diabetes 28, 852 (1979)

7. M. N. Goodman, N. B. Ruderman and T. T. Aoki, Diabetes 27, 1065 (1978)

8. G. Lukas, K. H. Vyas, S. D. Brindle, A. R. Le Sher and W. E. Wagner, J. pharm. Sci. 69, 419 (1980).

9. O. B. Evans and P. W. Stacpoole, Biochem. Pharmac. 31, 1295 (1982).

10. O. B. Evans, Archs Neurol., Chicago 38, 515 (1981).

11. L. T. Sancllo, Biochem. Med. 81, 345 (1973).

12. F. Demaugre, C. Cepanec and J. P. Leroux, Biochem. biophys. Res. Commun. 85, 1180 (1978).

\title{
Inhibition of carrageenin-induced rat footpad edema by systemic treatment with prostaglandins of the $E$ series
}

\author{
(Received 4 December 1981; accepted 25 March 1982)
}

One of the most widely used models for evaluation of anti-inflammatory agents is carrageenin-induced edema in the rat footpad [1]. This reaction consists of three distinct phases of mediator-induced vascular permeability changes. The initial phase, during the first $30 \mathrm{~min}$ after injection, results from the release of histamine and serotonin from host cells and is inhibited hy anti-histamines [2]. The second phase, between 1 and $2.5 \mathrm{hr}$ after injection, is attributed to the action of bradykinin since pretreatment of rats with cellulose sulfate (which lowers plasma kininogen levels) reduces edema. The third phase of persistent edema is complement-dependent and has been attributed to the local production of prostaglandins, especially of the E series, by inflammatory cells [3-6]. This phase of edema formation is inhibited by indomethacin and aspirin, and is potentiated by the local injection of vasodilatory prostaglandins such as $\mathrm{PGE}_{2}[7,8]$. However, additional studies suggest that stimulation of prostaglandin production may have inhibitory effects on carrageenin-induced edema [9]. Recent studies in our laboratory have shown that systemic treatment of rats with prostaglandins, especially of the E series, will inhibit vascular permeability changes induced by the vasoactive mediators histamine, serotonin, bradykinin, compound $48 / 80$ and the anaphylatoxin C3a [10]. In this report, we examine the effects of systemic prostaglandin treatment of rats on carrageenin-induced vascular permeability changes.
Carrageenin edema was induced by the intradermal injection of $0.1 \mathrm{ml}$ of $1 \%$ carrageenin (viscarin 402) (Marine Colloids, Springfield, NJ), dissolved in phosphate-buffered saline (PBS), pH 7.4, into the hind paw of Sprague-Dawley rats weighing $200-250 \mathrm{~g}$ (Charles River Laboratories, Portage, MI). Separate groups of three to five rats were pretreated (subcutaneously) with prostaglandins $1 \mathrm{hr}$ prior to carrageenin injection. Footpad thickness was measured at various times after carrageenin injection with a Mitutoyo micrometer. Prostaglandins (PG) were provided by $\mathrm{Dr}$ John Pike (Upjohn Co., Kalamazoo MI). Student's t-test (two tailed) was used to compare PG-treated animals with non-treated control animals.

The effect of systemic treatment of rats with 15-S-15methyl $\mathrm{PGE}_{1}$ (15-M-PGE $)$ on carrageenin-induced footpad edema is shown in Fig. 1. When 15-M-PGE 1 at a dose of $1 \mathrm{mg} / \mathrm{kg}$ was administered s.c. $1 \mathrm{hr}$ prior to carrageenin injection, there was significant inhibition of rat footpad edema formation as compared to control values. Both the acute phase $(47.1 \%$ inhibition at $1 \mathrm{hr}, \mathrm{P}<0.001)$ of edema formation mediated by histamine, serotonin, and bradykinin and the later phase $(61.0 \%$ inhibition at $6 \mathrm{hr}$, $P<0.001$ ) which is inhibited by indomethacin and aspirin were reduced significantly. Inhibition of footpad edema formation by $15-\mathrm{M}-\mathrm{PGE}_{1}$ was dose dependent with significant inhibition $(40.7 \%$ at $1 \mathrm{hr}, \mathrm{P}<0.001$ and $37.7 \%$ at $6 \mathrm{hr}, \mathrm{P}<0.001$ ) occurring at a dose of $0.2 \mathrm{og} / \mathrm{kg}$ and only 


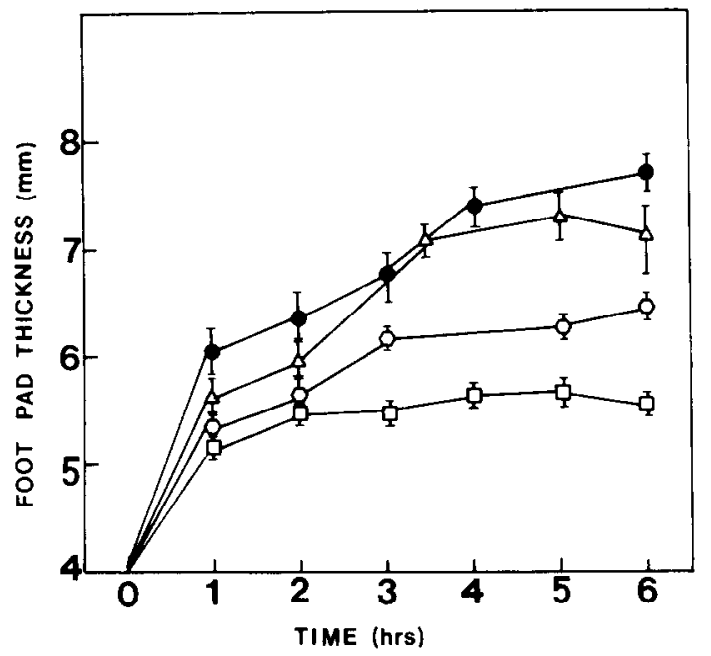

Fig. 1. Effect of systemic treatment of rats with 15-S-15methyl $\mathrm{PGE}_{1}$ on carrageenin-induced footpad edema. Groups of four rats received $15-\mathrm{M}-\mathrm{PGE}_{1}$ at various doses s.c. $1 \mathrm{hr}$ prior to injection of carrageenin into the rat footpad. Footpad thickness was measured at $1 \mathrm{hr}$ intervals after carrageenin injection. The mean value for each group of four animals is shown \pm the standard error of the mean. Key: $(O)$ control; $(\triangle)$ 15-M-PGE $1,0.04 \mathrm{mg} / \mathrm{kg}$; (D) $15-$ $\mathrm{M}-\mathrm{PGE}_{1}, 0.2 \mathrm{mg} / \mathrm{kg}$; and $(\square)$ 15-M-PGE $1,1 \mathrm{mg} / \mathrm{kg}$.

slight inhibition of edema formation at a dose of $0.04 \mathrm{mg} / \mathrm{kg}$.

The specificity of the inhibition of carrageenin-induced edema is shown in Fig. 2. When prostaglandins were administered $1 \mathrm{hr}$ prior to carrageenin treatment at concentrations of $1 \mathrm{mg} / \mathrm{kg}, 15-\mathrm{M}-\mathrm{PGE} \mathrm{E}_{1}$ showed the greatest inhibition of edema formation (see above) while $\mathrm{PGE}_{1}$ (49.5\% inhibition at $6 \mathrm{hr}, \mathrm{P}<0.001)$ and $\mathrm{PGE}_{2}(34.4 \%$ inhibition at $6 \mathrm{hr}, \mathrm{P}<0.001)$ at the same concentration showed significant inhibition of only the later phase of edema formation. Treatment of rats with $\mathrm{PGF}_{2 \alpha}$, a potent

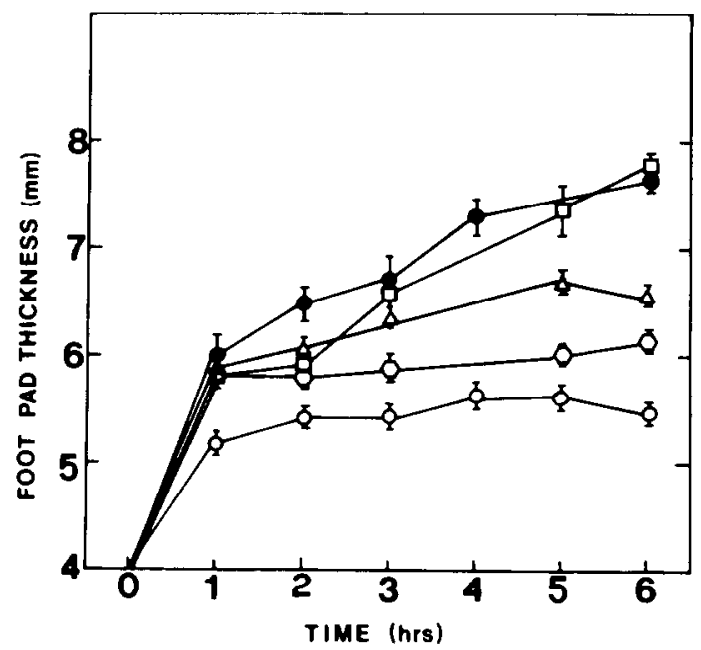

Fig. 2. Effects of systemic treatment of rats with 15-S-15methyl $\mathrm{PGE}_{1}, \mathrm{PGE}_{1}, \mathrm{PGE}_{2}$ and $\mathrm{PGF}_{2 \alpha}$ on carrageenininduced footpad edema. Groups of four rats received individual prostaglandins $(1 \mathrm{mg} / \mathrm{kg})$ s.c. $1 \mathrm{hr}$ prior to injection of carrageenin into the rate footpad. Footpad thickness was measured at 1 -hr intervals after carrageenin injection. The mean value for each group of four animals is shown \pm the standard error of the mean. Key: $(O)$ control; $(\square)$ $\mathrm{PGF}_{2 \alpha} ;(\triangle) \mathrm{PGE}_{2} ;$ (D) $\mathrm{PGE}_{1}$; and (O) 15-M-PGE vasoconstrictor [11], had no effect on carrageenin-induced edema formation. The difference in activity between 15 $\mathrm{M}-\mathrm{PGE}_{1}$ and $\mathrm{PGE}_{1}$ is most likely a result of the increased stability and resistance to hydrolysis by 15 -hydroxyprostaglandin dehydrogenase of the 15-methyl analog [12].

The time dependence of the inhibitory effect of $15-\mathrm{M}$ $\mathrm{PGE}_{1}$ on edema formation is shown in Fig. 3. Significant inhibition of both the early and late phases of carrageenin-induced edema was observed when animals received carrageenin at 1 (see above) and $24(39.0 \%$ inhibition at $1 \mathrm{hr}, \mathrm{P}<0.001$, and $41.3 \%$ inhibition at $6 \mathrm{hr}$, $P<0.001) \mathrm{hr}$ after treatment with $15-\mathrm{M}-\mathrm{PGE}_{1}(1 \mathrm{mg} / \mathrm{kg}$, s.c.). However, when animals were challenged at $48 \mathrm{hr}$ after $15-\mathrm{M}-\mathrm{PGE}_{1}$ treatment, there was only minimal inhibition (12.6\% inhibition at $6 \mathrm{hr}$ ) of edema formation.

The data presented here show that systemic treatment of animals with prostaglandins of the E series will inhibit carrageenin-induced edema in the rat footpad in both a dose- and time-dependent manner. In addition, the inhibitory effects of PGs on carrageenin-induced edema formation show at least partial specificity for PGs of the E series since $\mathrm{PGF}_{2 \alpha}$ had no effect.

Inhibition of the earlier phases of carrageenin-induced permeability changes by $\mathrm{PGE}_{1}$ and $\mathrm{PGE}_{2}$ is consistent with initial studies in which systemic treatment of rats with $\mathrm{PGE}_{1}$ and $\mathrm{PGE}_{2}$ inhibited edema formation induced by histamine, bradykinin and serotonin [10] as well as other acute and chronic inflammatory reactions $[4,13-15]$. The inhibition of edema formation at 3-6 hr after carrageenin treatment by $P G E_{1}$ and $P E_{2}$ suggests that there are marked differences between the local and systemic effects of prostaglandins on acute inflammatory reactions. Several authors have shown that the local injection of prostaglandins of the E series will potentiate leakage of plasma proteins due to histamine, bradykinin, and carrageenin secondary to PGE-induced vasodilation $[4,7,16-18]$. However, the dose of locally administered PGE is frequently in the range of $1 \mu \mathrm{g}$, and it is unlikely that s.c. administration of $15-\mathrm{M}$ $\mathrm{PGE}_{1}$ at $0.2 \mathrm{mg} / \mathrm{kg}$ or $\mathrm{PGE}_{2}$ at $1.0 \mathrm{mg} / \mathrm{kg}$ resulted in comparable local concentrations $1 \mathrm{hr}$ later. Therefore, the con-

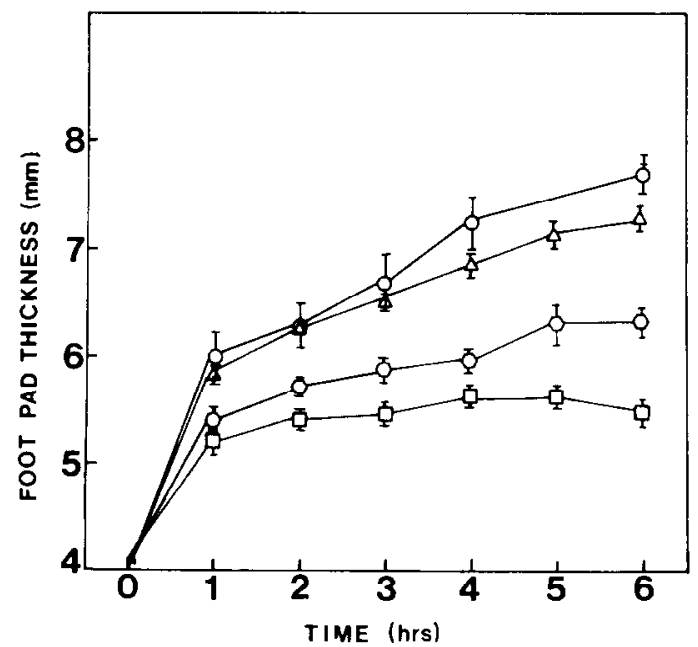

Fig. 3. Time dependence of the inhibitory effect of 15 $\mathrm{M}-\mathrm{PGE}_{1}$ on carrageenin-induced footpad edema. 15-M$\mathrm{PGE}_{1}(1 \mathrm{mg} / \mathrm{kg}$, s.c.) was administered 1,24 and $48 \mathrm{hr}$ to groups of four animals prior to injection of carrageenin into the rat footpad. Footped thickness was measured at 1-hr intervals after carrageenin injection. The mean value for each group of four animals is shown \pm the standard error of the mean. Key: $(O)$ control; $(\square)$ 15-M-PGE administered $1 \mathrm{hr}$ prior to carrageenin injection; (O) 15$\mathrm{M}-\mathrm{PGE}_{1}$ administered $24 \mathrm{hr}$ prior to carrageenin injection; and $(\triangle)$ 15-M-PGE 1 administered $48 \mathrm{hr}$ prior to carrageenin injection. 
trasting effects between systemic and local administration of PGEs may reflect a dose effect of PGEs on the vascular wall and edema formation.

Additional studies have demonstrated increased levels of $\mathrm{PGE}_{2}$ in exudates at $3-6 \mathrm{hr}$ after carrageenin administration $[8,18]$. Although this later phase of edema formation is inhibited by aspirin and indomethacin [2,3], this is only indirect evidence implicating $\mathrm{PGE}_{2}$ as a proinflammatory agent. It is possible that the increased level of $\mathrm{PGE}_{2}$ previously reported in acute carrageenin inflammatory sites is not the causative agent of the persistent edema. Several authors have shown that the so-called prostaglandin phase of vascular permeability change is dependent on the generation of superoxide anion $\left(\mathrm{O}_{2}^{-}\right)$and is inhibited by superoxide dismutase and specific scavengers of oxygen-derived free radicals [19]. Since oxygen-derived free radicals and their metabolites have been shown to cause tissue injury, it is possible that their production is responsible for the delayed carrageenin-induced edema formation [20-22].

Recent studies have also shown that the effects of indomethacin and aspirin are not as specific as originally described. Since both compounds have been shown to inhibit the production of lipoxygenase products of arachidonic acid metabolism [23, 24], and indomethacin to inhibit oxygen free radical production [25] and release of lysosomal enzymes from inflammatory cells [25,26], it is possible that the delayed permeability changes induced by carrageenin are not secondary to $P \mathrm{PE}_{2}$, as previously described, but are the result of the local production of lipoxygenase products and/or oxygen-derived free radicals. The increased PGE levels demonstrated in early acute inflammatory reactions may, in fact, represent a modulating system that controls and limits the extent of the inflammatory response.

The data demonstrate that systemic treatment of rats with prostaglandins of the $\mathrm{E}$ series inhibited carrageenininduced edema formation. In addition, not only were the acute changes in vascular permeability inhibited but the delayed persistent permeability change previously attributed to the local generation of prostaglandins was also suppressed. The data support the previously described anti-inflammatory effects of systemic treatment with prostaglandins of the E series in vivo and suggest that they may be of future use in therapeutic modulation of edema formation and inflammatory reactions.

\section{Department of Pathology \\ University of Michigan Medical \\ School}

Ann Arbor, MI 48109, U.S.A.

JOSEPH C. FANTONE*

STEVEN L. KUNKEL

BRENDA WEINGARTEN

* Supported in part by NIH Grant HL-00905.

† Author to whom correspondence should be addressed.

\section{REFERENCES}

1. C. A. Winter, E. A. Risley and G. W. Nuss, Proc. Soc. exp. Biol. Med. 111, 544 (1962).

2. M. Dirosa, J. P. Giroud and D. A. Willoughby, $J$. Path. 104, 15 (1971)

3. R. Vinegar, W. Schreiber and R. Hugo, J. Pharmac. exp. Ther. 166. 96 (1969).

4. G. Thomas and G. B. West, Br. J. Pharmac. 50, 231 (1974).

5. P. Velo, C. J. Dunn, J. P. Giroud, J. Timsit and D. A. Willoughby, J. Path. 111, 149 (1973).

6. A. L. Willis, J. Pharm. Pharmac. 21, 126 (1969).

7. ' I. J. Williams and J. Morley, Nature, Lond. 246, 215 (1973).

8. I. L. Bonta and M. J. Parnham, Br. J. Pharmac. 65 , 465 (1979)

9. J. Robak, E. Kostka-Trabka and Z. Duniel, Biochem. Pharmac. 29, 1863 (1980).

10. J. C. Fantone, S. L. Kunkel, P. A. Ward and R. B. Zurier, J. Immun. 125, 2591 (1980).

11. M. Echt, O. H. Gauer, F. Kapteina and L. Lange, in Advances in the Biosciences, Ninth International Conference on Prostaglandins (Ed. S. Bergstrom), p. 353. Pergamon Press, Oxford (1972).

12. H. S. Hansen, Prostaglandins 12, 647 (1976).

13. R. B. Zurier and F. Quagliata, Nature, London. 234, 304 (1971).

14. S. L. Kunkel, R. S. Thrall, R. G. Kunkel, J. R. McCormick, P. A. Ward and R. B. Zurier, J. clin. Invest. 64. 1525 (1979).

15. S. L. Kunkel, J. C. Fantone, P. A. Ward and R. B. Zurier, Prog. Lipid Res. 20, 633 (1982).

16. M. Mannik, Arthritis and Allied Conditions (Ed. D. J. McCarty), p. 256. Lea \& Febiger, Philadelphia (1979).

17. G. Thomas, Prostaglandins 19, 39 (1980).

18. I. L. Bonta and M. J. Parnham, Eur. J. Rheum. Inflam. 2, 97 (1979).

19. Y. Oyanagui, Biochem. Pharmac. 25, 1465 (1976).

20. S. J. Klebanoff, Ann. intern. Med. 93, 480 (1980).

21. J. R. McCormick, M. M. Harkin, K. J. Johnson and P. A. Ward, Am. J. Path. 102, 55 (1981).

22. K. J. Johnson, J. C. Fantone, J. Kaplan and P. A. Ward, J. clin. Invest. 67, 983 (1981).

23. M. I. Siegel, R. T. McConnell, N. A. Porter, J. L. Selph, J. F. Truax, R. Vinegar and P. Cuatrecasas, Biochem. biophys. Res. Commun. 92, 688 (1980).

24. R. W. Randall, K. E. Eakin, G. A. Higgs, J. A. Salmon and J. E. Tateson. Agents Actions 10, 553 (1980)

25. G. M. Bokoch and P. W. Reed, Biochem. biophys Res. Commun. 90, 481 (1979).

26. J. E. Smolen and G. Weissman, Advances in Prostaglandins and Thrombofane Research (Eds. B. Samuelsson, P. W. Ramwell and R. Paoletti), Vol. 8, p. 1695. Raven Press, New York (1980).

\title{
Methylation of norepinephrine and $\alpha$-methylnorepinephrine in brain
}

\author{
(Received 11 January 1982; accepted 13 April 1982)
}

Because of the anatomic location of epinephrine-forming neurons in rat brain, attention has been focused recently on their possible rolc in the central regulation of blood pressure $[1-3]$. The possibility that some antihypertensive drugs act by influencing epinephrine-forming neurons or receptors for these neurons in brain has also been suggested [2-5].

Recently, Beart et al. $[6,7]$ have reported that $\alpha$-meth- 